\title{
A Mobile-based Neuro-fuzzy System for Diagnosing and Treating Cardiovascular Diseases
}

\author{
Folasade O. Isinkaye \\ Ekiti State University/Department of Computer Science, Ado-Ekiti, Nigeria \\ Email: sadeisinkaye@gmail.com \\ Jumoke Soyemi and Olayinka P. Oluwafemi \\ Federal Polytechnic/Department of Computer Science, Ilaro, Nigeria \\ Ekiti State University/Department of Computer Science, Ado-Ekiti, Nigeria \\ Email: \{jumoke.soyemi@federalpolyilaro.edu.ng, olayinkapeter99@gmail.com\}
}

Received: 04 November 2016; Accepted: 16 December 2016; Published: 08 November 2017

\begin{abstract}
In our present environment, heart diseases are very rampart and they describe the various types of diseases that affect the heart. They account for the leading cause of death word-wide especially, in Africa. It is therefore very important for individuals to have adequate knowledge of their heart health in order to avoid the risk of decreased life expectancy. The high mortality rate of heart (cardiovascular) diseases is attributed to the unequal ratio of patients to scarcity of medical experts who can provide medical care, also patients are not always warned to waiting long hours on queue in the hospital, especially in cases of emergency. This paper designed and implemented a Mobile Neuro-fuzzy System that uses the combination of the intelligent technique of Artificial Neural Networks (ANN) and the human-like reasoning style of Fuzzy Logic to diagnose and suggest possible treatments for cardiovascular diseases through interactivity with user. It employs programs like MySQL, PHP, JAVA (Android) and XML (Android Studio) while tools like XAMPP, PhpStorm and Android O/S were used to integrate these techniques together. The system proved to be of enormous advantage in diagnosing heart diseases, as it diagnoses and learns about each user per time, to provide adequate and appropriate results and also makes reliable predictions to users.
\end{abstract}

Index Terms-Heart disease, Neuro-fuzzy system, Artificial Neural network, Intelligence Technique, Android.

\section{INTRODUCTION}

Cardiovascular diseases encompass the various diseases that affect the heart and they are the leading cause of death word-wide [1] especially, in Africa. The American Heart Association (AHA) estimates that 17.3 million death cases are recorded per year, a number that is expected to grow to more than 23.6 million by 2030 [2]. Heart failure was reported as the primary diagnosis for hospitalization among medical care beneficiaries [3] There are different kinds of cardiovascular diseases which include coronary artery diseases [4] such as angina and myocardial infarction which is popularly called heart attack [5]The other common heart diseases are stroke, hypertensive heart disease [6], rheumatic heart disease, cardiomyopathy, atrial fibrillation, congenital heart disease, endocarditis, peripheral artery disease and venous thrombosis. The high mortality rate of cardiovascular diseases is attributed to the unequal ratio of patients to scarcity of medical experts who can provide medical care. This mortality rate has constantly drawn the attention of researchers and different soft computing techniques have been deployed to reduce this rate and to serve very large amount of patients in less time [7]. Presently, most of these researches focus on modeling parts of human body and recognizing diseases from different scans such as cardiograms, CAT scans (Computerized Axial Tomography scan), ultrasonic scans, and others [8]. This paper developed a Mobile Neurofuzzy system that uses the combination of the adaptive intelligence of Artificial Neural Networks (ANN) and Fuzzy Logic to diagnose and suggest possible treatments for cardiovascular diseases.

The rest of the paper is organized as follows; Section II reviews related work on Artificial Neural Network and Fuzzy Logic, Section III introduces the design detail of the proposed system while Section IV describes the implementation details of the system and Section V concludes the paper.

\section{RELATED WORKS}

Artificial Neural Networks (ANN)[9] and Fuzzy logic [10][11] (popularly known as Neuro-Fuzzy) are currently drawing research attention in the area of medical science. Application of ANN in medical science includes modeling and diagnosing cardiovascular disorders [1][12] classification and diagnostic prediction of cancers [13], diagnosis of urological dysfunctions diabetes disease diagnosis [14]. They are used in the analysis of medical images from a variety of imaging modalities [15]. 
Neural network as a classification technique in data mining can be applied to extract rules from diseases in medical diagnosis [10][16][17]. From the rules, analysis and prediction of diseases could be done easily. Different variations of ANN have been employed to help alleviate the problem of diagnosis, treatment and medical advice provisioning in medicine [18][19][20][21]. For example, [7] designed a Fuzzy Expert System for heart disease diagnosis. The system has thirteen input fields and one output field. Input fields consist of heart disease symptoms. The output field refers to the presence of heart disease in the patient. It uses integer valued from 0 (no presence) to 4 to distinguish levels of presence of the disease. The system can be used as an alternative for existing systems to distinguish the presence or absence of heart disease

Vazirani [22] proposed a modular neural network for the diagnosis of heart disease. The system used two types of diagnosis methods which include manual and automatic diagnosis. The attributes of both methods are divided and given to the two neural network models, Backpropagation Neural Network (BPNN) and Radial Basis Function Neural Network (RBFNN) for training and testing. The results of the two techniques were integrated and provided the final training accuracy and testing accuracy

Ansari \& Gupta [23] proposed a computational intelligence technique which combined fuzzy systems, neural network and evolutionary computing for the diagnosis of coronary heart disease. In order to show the effectiveness of the proposed system, Simulation for automated diagnosis was performed using the realistic causes of coronary heart disease. Also, in the system, it was observed that maximum classification accuracy was obtained in NFIS (Neuro-Fuzzy Integrated System) training result.

Soltan and colleagues [24] described a prototype model of an expert system for diagnosing and treatment of two types of heart diseases. The system used a rule-based reasoning technique through simple querying of symptoms, signs and investigation done to the patient. Programs such as CLIPS and PROLOG were used for diagnosis and system analysis. The system according to the study was able to diagnose heart diseases in patient and provide treatment.

Also the study by Chen and colleagues [25] proposed a healthcare management system, named CardicGuard, which specialized in monitoring and analyzing heart disorder in the elderly. The CardiaGuard cloud is an expert system designed based on hybrid classifier implemented using Support Vector Machine (SVM) and Random Tree (RT) classification algorithm. A comprehensive performance evaluation showed that the proposed hybrid classification engine is able to detect six different types of cardiac disorders with higher accuracy than the SVM-based classifier. Also [26] proposed a novel approach based on MLP Back Propagation Neural Network for the prediction of heart disease. The proposed system used about thirteen important medical attributes for heart disease predictions.
In this study, we considered the development of Mobile Neuro-fuzzy System that uses the combination of the intelligence technique of Artificial Neural Networks (ANN) and the human-like reasoning style of Fuzzy Logic to diagnose [27][28][29] and suggest possible treatments for cardiovascular diseases through interactivity with user [30]. Taking the advantage of mobile technology in term of phones that are cheaply available and with the widespread accessibility to provide real time healthcare services. The mobile system will have a great potential in empowering patients and reshaping the expectations of healthcare service delivery thus making it people-centered. Also the system will assist government to cope with increasing demands for healthcare deliveries.

\section{DESIGN OF THE PROPOSED SYSTEM}

The solution proposed for medical system in this paper is the development of a Mobile-based Neuro-fuzzy system for diagnosing and treating cardiovascular diseases. A brief description of the system and its functions are outlined as follows.

\section{System Description}

The proposed medical system for the heart diseases diagnosis is illustrated in the figure 1 below, describing its design concept, components and how they interact with one another.

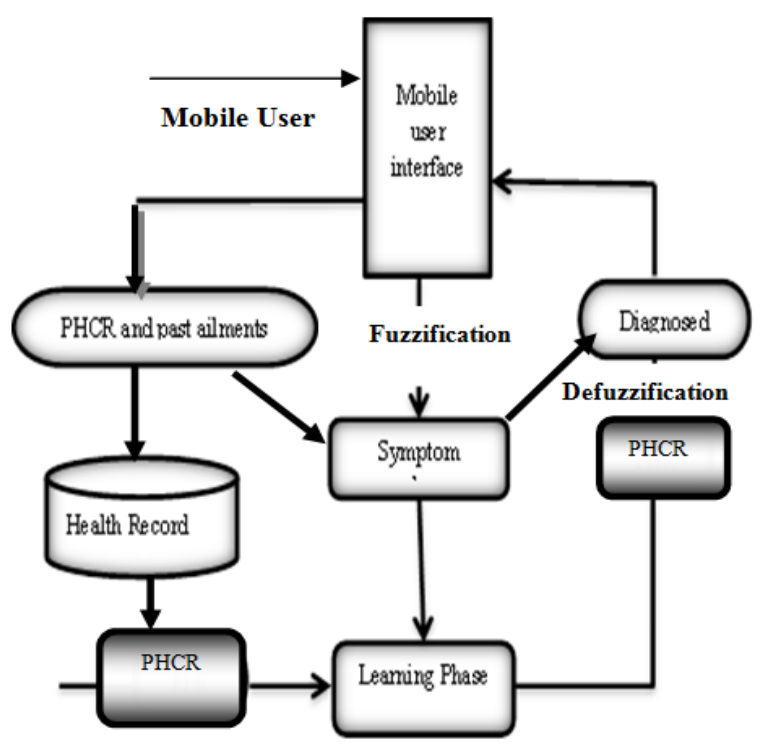

Fig.3.1. Proposed Medical System Model

Figure 1 depicts the proposed system where patients interact with the system through the user interface by supplying their Personal Healthcare Record (PHCR) details such as the ailments and the present symptoms. The work of the user interface is to send the PHR data and past ailments to the health record database, and sends the present symptoms to the symptom checker; this is called the fuzzy process. The symptom checker is responsible for matching the symptoms with appropriate 
rules, by working with the user interface until one or some of the heart conditions are satisfied. The results are then sent to the Learning phase which is the Neural Network phase for further diagnosis. Since the module has already acquired enough knowledge of patient from the Health record database, it intelligently connects the remaining parts, checking to detect the cause of heart disease and then, produces a final result which is accessed by the user through the mobile interface.

Figure 2 shows the Neuro-fuzzy process as implemented in the proposed medical system model. Fuzzification module accepts variables $\left(\mathrm{x}_{1}-\mathrm{x}_{\mathrm{m}}\right)$, in this case, they are patient symptoms (such as stroke level, blood pressure, cholesterol level, maximum heart rate, chest pain type and blood sugar and etc) and determine their membership values as very low, low, moderate, high and very high as the case may be. Every input sends a fuzzy valued signal to each fuzzy rule-based module. It then determines the optimal number of IF-THEN fuzzy rules $\left(\mathrm{m}_{1}-\mathrm{m}_{\mathrm{p}}\right)$ which is equivalent to finding a suitable number of clusters for the given variables. The behavior of any fuzzy systems depends upon the set of fuzzy rules on which it is based like:

\section{IF <premise > THEN <consequent>}

Finally, the Defuzzification module transforms the resultant fuzzy values into a numerical value. The intelligence of this module is in its ability to compare fuzzy outputs values with previous patient data which includes the personal healthcare record (PHR).

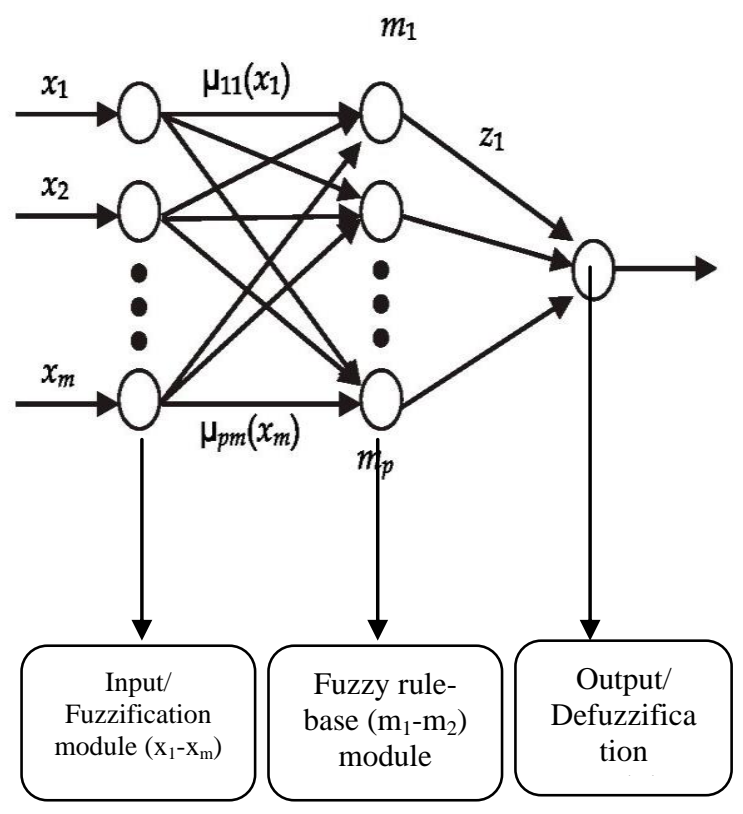

Fig. 3.2. Neuro-Fuzzy process

\section{IMPLEMENTATION OF THE PROPOSED System}

The implementation phase comprises of the tools, and technologies used in executing the design. That is, the type of tools that were used and the system requirements. It also shows the operation of the system, followed by the screen shots of the implementation of the system with interaction process between the user and the system.

\section{A. Tools and Technology Used}

The technologies employed are MySQL, PHP, JAVA (Android), and XML (Android). The tools for integration of the different technologies include Xampp, PhpStorm, and Android Studio. For the server-side, MySQL was used as the RDBMS (Relational Database Management System) language for the database while PHP was used to design the use cases (rules and procedures) and carry out the algorithmic functions, as it works with MySQL queries, and JSON format to output responses. For the Mobile back-end, JAVA, which is the Android programming language makes the HTTP POST and GET calls to communicate with PHP scripts and then activates the responses in JSON format. For the Mobile front-end, XML (Extensible Mark-up Language) functions as interface language, the tools were used to design and arrange the different layouts, menu and the entire interaction process, including the chat activity, navigations, text fields, buttons, and so on for the mobile application. The choice of local server is Xampp since it helps to run apache, MySQL, and enable PHP queries. PhpStorm serves as a perfect IDE for PHP because it can also connect to the local server and show the database. Finally, Android Studio serves as the IDE for the mobile implementation. It was chosen because of the ease and flexibility of working with the tools as well as the large support of materials and user community using the development tools on a daily basis. Since the system is built to run on the Android operating system (Android $\mathrm{O} / \mathrm{S}$ ), it can only work for Android phones with following requirements: O/S Version: Android 4.2 (Jellybean) and above. RAM: 512 MB (Minimum).

\section{B. The Operations of the Proposed Mobile System}

When the application is initially launched, a user is required to either 'Login' as an existing user, or to 'Register' as a new user. After registration, the user is expected to enter his/her health details. These data are parsed with JSON to the database, and then the home screen comes up, which is a container of diverse fragments, navigated through by a Navigation drawer.

The diagnosis process begins as the user inputs his/her symptom(s), the single symptom entry is collected by a method in a Java class in the Android application package, and sent to a PHP script on the server. This script takes the responsibility of querying the database for whichever heart conditions that has the particular case as one of its symptoms, then begins to search for other possible conditions by sending more symptoms for the user to choose from, together with more descriptive detail from the user, before finally coming up with a singular heart condition, and then providing adequate medical information concerning the suspected condition. The conditions phase works with a method in java that makes a network call to a script which queries the entire list of conditions with their details, and displays them on the interface for the user to comfortably view through, and 
learn from. The PHR phase simply collects updated personal health records as inputs and sends them to another script on the server which updates the tables of the user in the database. The fourth phase shows a number of medical calculations related to heart health, with the inputs derived from already saved user data, e.g. height and weight for body mass index. Under the 'More' caption in the navigation drawer, the 'About app' is an activity that shows the details of the system, the developer and the system's social platforms. And 'Logout' works as a method in Java that closes the current user's right to use the application, it moves the user to the Login screen, thereby requiring his/her login details afresh.

\section{Screen Shots of the Implementation}

The following section displays some of the implementation screen shots of the mobile heart diagnosis application.

\section{The User Login/Register:}

In figures below, a user is expected to either Login as an existing user, or to register as a new user. All of these data are parsed with JAVA to the server and saved in the database.

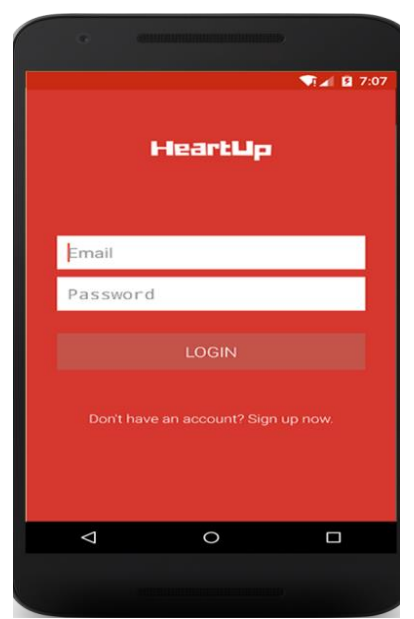

Fig.4.1: Login

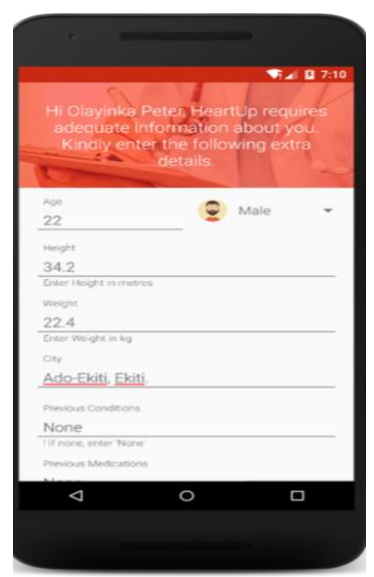

Fig. 4.3. PHR

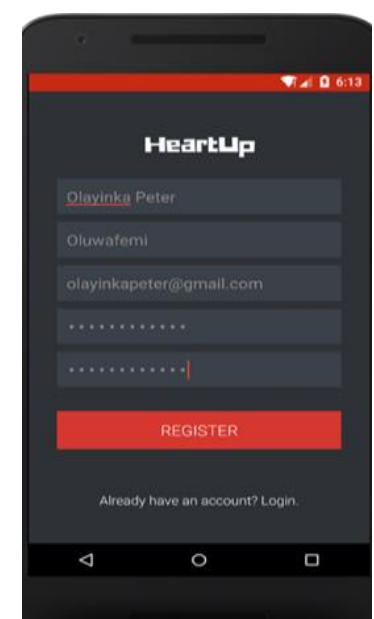

Fig. 4.2: Login

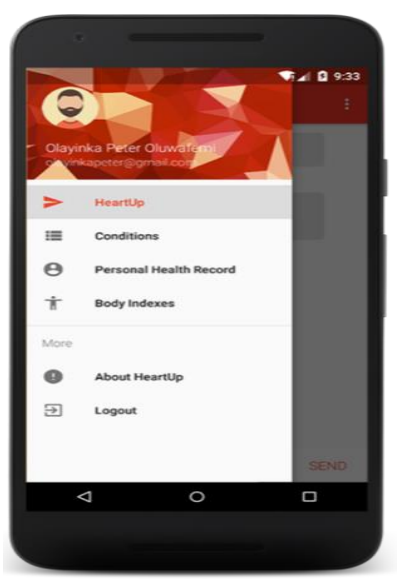

Fig. 4.4: PHR

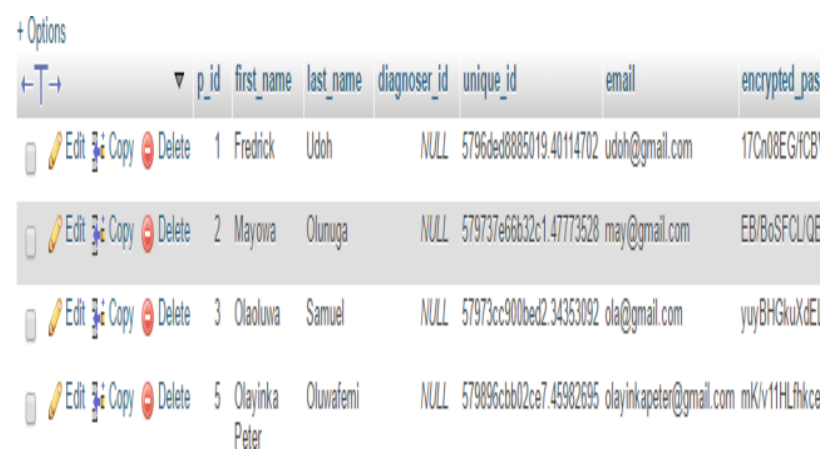

Fig.4.5. User login details saved to the database after Registration

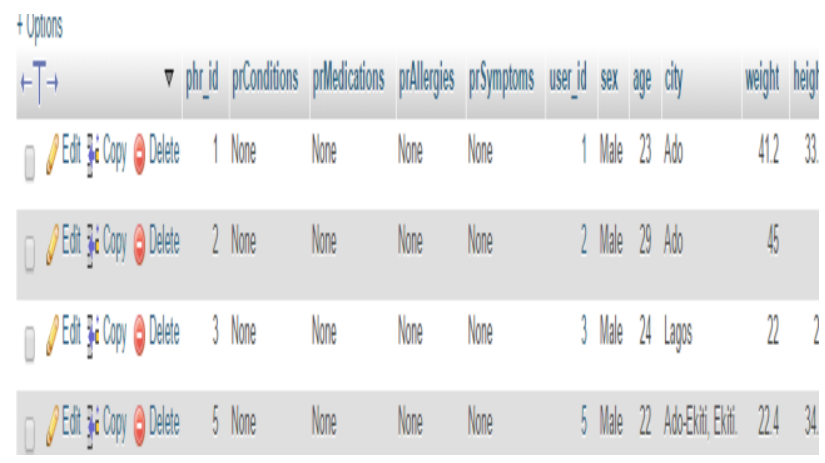

Fig.4.6. User personal health data saved to database after Registration

\section{Heartup (Chart Activities)}

Heartup functions as an interactive activity (Chat) that collects symptoms (inputs) from users via their chat entries, and parses them to the server as cases for diagnosis.

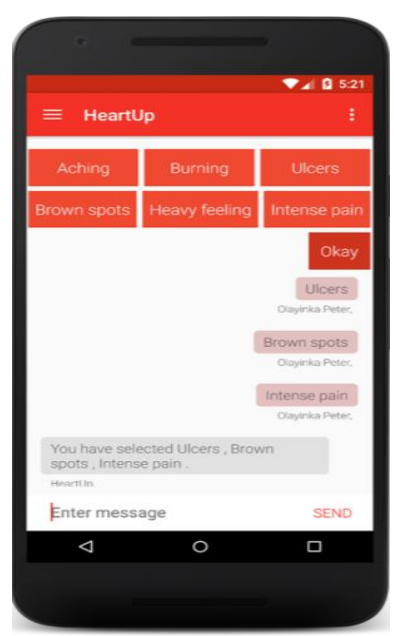

Fig.4.7. Chat Diagnosis

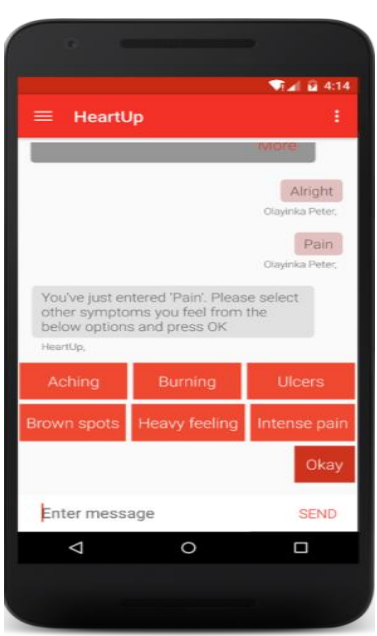

Fig.4.8. Chat Diagnosis 


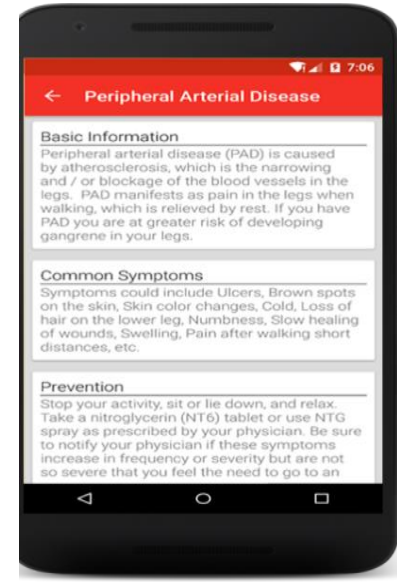

Fig.4.9. Chat Diagnosis

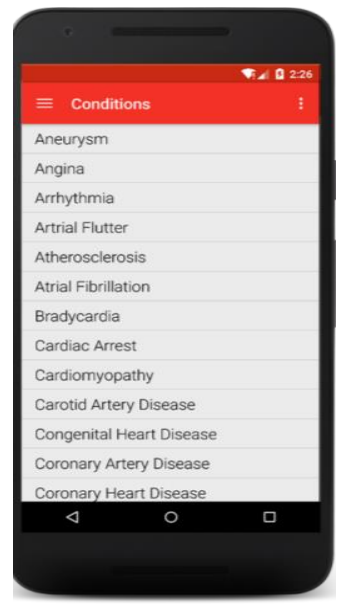

Fig.4.11. Condition List Fig.4.12. Condition (Angina description)

\section{Personal Health Record}

Figures 14 and 15 enables user to perform the duty of displaying existing user's personal health records, enabling the user to update these data and save the updated details, parsing them to the database.

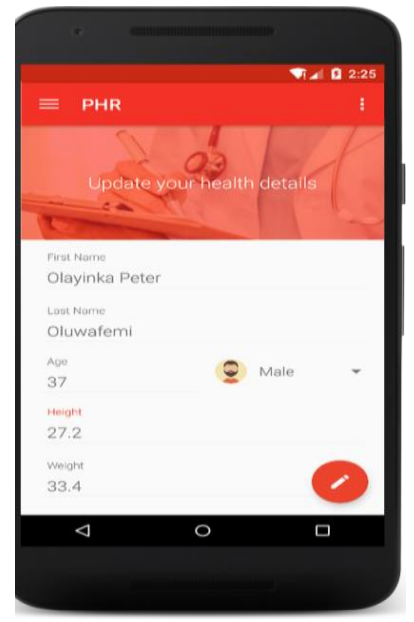

Fig.4.13. Update PHR
Fig. 4.16. About app

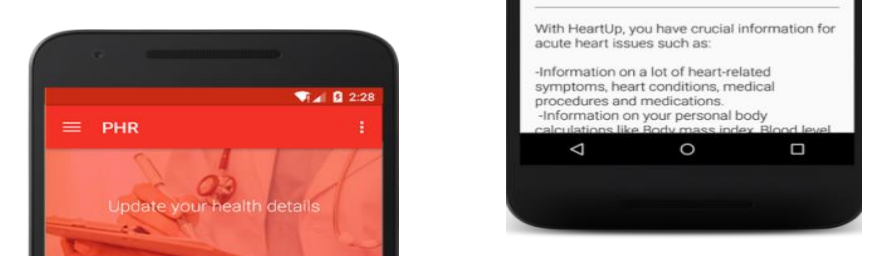

Fig. 4.17. About app (collapsed)

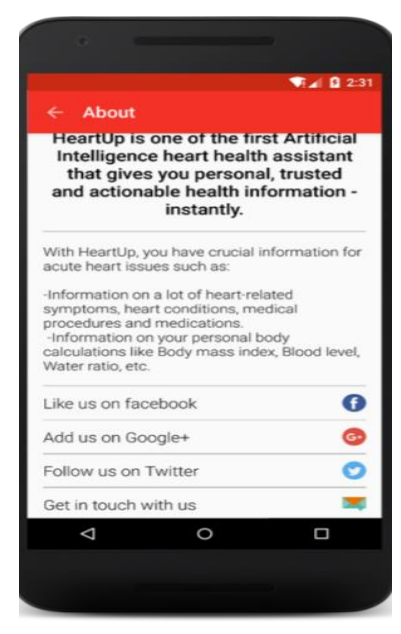

\section{Logout}

The Logout option is only a method that logs out the current user and sets the system's session to 'no user logged in', so that when the same or another user launches the app another time, it requests for login credentials. 


\section{EXPERIMENTAL EVALUATION OF THE SySTEM AND DISCUSSION}

Ten (10) respondents were selected randomly for the evaluation of the proposed system. They were asked to use the system to determine the speed, accuracy and ease of user interactivity with the system and the results are presented in the Table 1.

Table 5.1. Experimental result for the usability of the proposed system

\begin{tabular}{|c|c|c|c|c|}
\hline Respondents & $\begin{array}{l}\text { Nature of } \\
\text { Symptom }\end{array}$ & Speed & Accuracy & Interactivity \\
\hline $\mathbf{A}$ & $\begin{array}{c}\text { Complex } \\
\text { symptoms }\end{array}$ & $45 \%$ & $70 \%$ & $50 \%$ \\
\hline B & $\begin{array}{c}\text { Simple/C } \\
\text { ommon } \\
\text { symptoms }\end{array}$ & $90 \%$ & $60 \%$ & $100 \%$ \\
\hline $\mathrm{C}$ & $\begin{array}{c}\text { Complex } \\
\text { symptoms }\end{array}$ & $40 \%$ & $72 \%$ & $30 \%$ \\
\hline D & $\begin{array}{c}\text { Simple/C } \\
\text { ommon } \\
\text { symptoms }\end{array}$ & $95 \%$ & $55 \%$ & $70 \%$ \\
\hline $\mathbf{E}$ & $\begin{array}{c}\text { Simple/C } \\
\text { ommon } \\
\text { symptoms }\end{array}$ & $80 \%$ & $58 \%$ & $100 \%$ \\
\hline $\mathbf{F}$ & $\begin{array}{c}\text { Complex } \\
\text { symptoms }\end{array}$ & $40 \%$ & $65 \%$ & $40 \%$ \\
\hline G & $\begin{array}{c}\text { Simple } \\
\text { symptoms }\end{array}$ & $95 \%$ & $55 \%$ & $30 \%$ \\
\hline $\mathbf{H}$ & $\begin{array}{c}\text { Simple } \\
\text { symptoms }\end{array}$ & $95 . \%$ & $2 \%$ & $50 \%$ \\
\hline $\mathbf{I}$ & $\begin{array}{c}\text { Complex } \\
\text { symptoms }\end{array}$ & $85 \%$ & $60 \%$ & $40 \%$ \\
\hline $\mathbf{J}$ & $\begin{array}{l}\text { Complex } \\
\text { symptoms }\end{array}$ & $85 \%$ & $35 \%$ & $35 \%$ \\
\hline
\end{tabular}

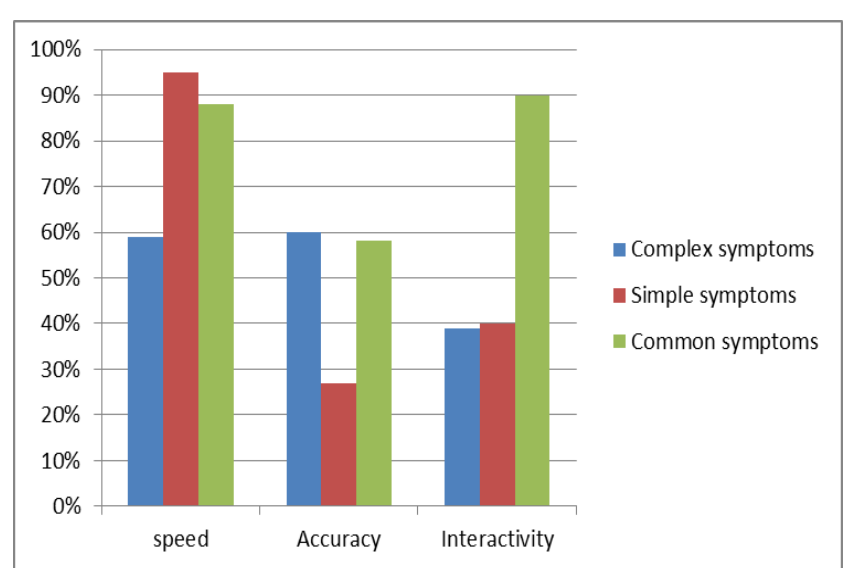

Fig.5.1. Chart result for usability of the proposed system

\section{DISCUSSION}

It was found that with simple and most common heartrelated symptoms, the system was able to diagnose faster, and had great interactivity, but the accuracy was relatively poor, compared to its other factors. The case was different with more complex symptoms, where the system diagnosed with a relatively longer time, had relatively poor user interactivity, but surprisingly produced a more accurate result than the diagnosis with simple symptoms.

\section{CONCLUSION}

In this paper the design and implementation of a Mobile Neuro-fuzzy System that uses the combination of the adaptive intelligent technique of Artificial Neural Networks (ANN) and the reasoning style of Fuzzy Logic to diagnose and suggest possible treatments for heart diseases through interactivity with users was achieved. It employs programs like MySQL, PHP, JAVA (Android) and XML (Android Studio) while platforms like XAMPP, PhpStorm and Android O/S were used to integrate these techniques together. The system was able to diagnose common heart-related problems faster and with powerful interactivity while also diagnosing complex symptoms with some levels of accuracy. The system is reliable and can be used on mobile systems to provide first hand assistance to patients where there is no immediate access to medical experts. The system can also compliment the efforts of medical experts.

\section{REFERENCES}

[1] E.P. Ephzibah and V. Sundarapandian, "A Neuro Fuzzy Expert System for Heart Disease Diagnosis", Computer Science \& Engineering, vol. 2 issue 1, pp. 17, 2012.

[2] American Heart Association, "Heart Disease and Stroke Statistics-At-a-Glance", Retrieved 12 September, 2016 from: http://www.onebraveidea.com/submissions/ucm 470704.pdf. 2011.

[3] H.M. Krumholz Y.T. Chen Wang Y.V. M. J. Radford, and R.I. Horwitz, "Predictors of Readmission among Elderly Survivors of Admission with Heart Failure", American heart journal, vol. 139 issue 1, pp. 72-77, 2000.

[4] Z. Mahmoodabadi, and M. S. Abadeh, "CADICA: Diagnosis of Coronary Artery Disease Using the Imperialist Competitive Algorithm", Journal of Computing Science and Engineering, vol. 8 issue 2, pp.87-93. 2014

[5] D.C. Gaze, Introduction to Ischemic Heart Disease. INTECH Open Access Publisher, 2013.

[6] M. Chen, M. and Dong,, "Intelligent Categorization Method for Diagnosing Cardiovascular Diseases Hierarchically", Journal of Automation and Control Engineering vol, 3 issue 6, pp. 512-518. 2015

[7] A. Adeli, and M. N, "A fuzzy expert system for heart disease diagnosis," In Proceedings of International Multi Conference of Engineers and Computer Scientists, Hong Kong, vol. 1. 2010.

[8] M.B. Wadhonkar P.A. Tijare and S.N. Sawalkar, "Classification of heart disease dataset using multilayer feed forward backpropogation algorithm", International journal of application or innovation in engineering \& management, vol. 2 issue 4, pp. 214-220, 2013.

[9] J. Dheeba, N. A. Singh, and S. T. Selvi, "Computer-aided detection of breast cancer on mammograms: A swarm intelligence optimized wavelet neural network approach", Journal of biomedical informatics, vol. 49, pp. 45-52. 2014 
[10] P. I. Singh, \& G. S. M. Thakur, "Enhanced password based security system based on user behavior using neural networks", International Journal of Information Engineering and Electronic Business", vol. 4 issue 2, pp. 29-35. 2013

[11] A. Yavari, M. Golbaghi, \& H. Momeni, "DAssessment of Effective Risk in Software Projects based on Wallace's Classification Using Fuzzy Logic", International Journal of Information Engineering and Electronic Business, vol. 5 issue 4, pp. 58-64, 2013

[12] A.S. Kumar, "Diagnosis of Heart Disease using Advanced Fuzzy Resolution Mechanism", International Journal of Science and Applied Information Technology, vol. 2 issue 2, pp. 22-30, 2013.

[13] M. Pourmandi and J. Addeh, "Breast Cancer Diagnosis Using Fuzzy Feature and Optimized Neural Network via the Gbest-Guided Artificial Bee Colony Algorithm", Computational Research Progress in Applied Science \& Engineering, vol. 1 issue 4, pp. 152-159, 2015.

[14] T.S. Zeki M.V. Malakooti Y. Ataeipoor and S.T. Tabibi, "An expert system for diabetes diagnosis". American Academic \& Scholarly Research Journal, vol. 4 issue 5 p. $1,2012$.

[15] B. Nagarajasri and M. Padmavathamma, "Threshold Neuro Fuzzy Expert System for Diagnosis of Breast Cancer". International Journal of Computer Applications, vol. 66 issue 8, pp. 6-10, 2013.

[16] K. Srinivas B.K. Rani and A. Govrdhan, "Applications of data mining techniques in healthcare and prediction of heart attacks". International Journal on Computer Science and Engineering, vol. 2 issue 2, pp. 250-255, 2010.

[17] C.S. Dangare and S.S. Apte, "Improved study of heart disease prediction system using data mining classification techniques", International Journal of Computer Applications, vol. 47 issue 10, pp. 44-48, 2012.

[18] T. Chaudhari, \& D. Agrawal, "Automatic detection of malaria parasites for estimating parasitemia" International Journal of Advance Research in Engineering, Science \& Technology, vol. 2 issue 12, 28-34. 2015

[19] F. Amato, A. López, E. M. Peña-Méndez, P.Vaňhara, A. Hampl, J. and Havel, "Artificial neural networks in medical diagnosis", Journal of applied biomedicine, vol. 1 issue 2, pp.47-58. 2013

[20] L. Kai, Y. Hua, X. Zhang Yunlong, Y. Zhehan, Z Yan, and M. Qun, "Improving Public Health Multidimensional Services through the Use of Smart Cloud Mode", International Journal of Smart Home, vol. 9 issue 8, pp.205-218. 2015

[21] O. Opeyemi. and E.O. Justice, "Development of Neurofuzzy System for Early Prediction of Heart Attack", International Journal of Information Technology and Computer Science, vol. 4 issue 9, pp. 22-28, 2012.

[22] H. Vazirani R. Kala A. Shukla and R. Tiwari, "Use of modular neural network for heart disease", International Journal of Computer and Communication Technology, vol. 1 issue 2-4, pp. 88-93, 2010.

[23] A.Q. Ansari and N.K. Gupta, "Automated Diagnosis of Coronary Heart Disease using Neuro-fuzzy Integrated System”, In 2011 World Congress on Information and Communication Technologies pp. 1383-1388, 2011

[24] R.A. Soltan M.Z Rashad, and B. El-Desouky, "Diagnosis of Some Diseases in Medicine via computerized Experts System", International Journal of Computer Science \& Information Technology, vol. 5 issue 5, pp. 79-90, 2013.

[25] H. Chen B.C. Cheng G.T. Liao and T.C. Kuo, "Hybrid classification engine for cardiac arrhythmia cloud service in elderly healthcare management", Journal of Visual
Languages \& Computing, vol. 25 issue 6, pp. 745-753. 2014.

[26] M. Durairaj, and M. Revathi, "Prediction of Heart Disease Using Back Propagation MLP Algorithm", International Journal of Scientific \& Technology Research, vol. 4 issue 8, pp. 235-239, 2015.

[27] K. B. Mankad, "Design of Genetic-Fuzzy Based Diagnostic System to identify Chikungunya", International Research Journal of Engineering and Technology, vol. 2 issue 4, pp. 153-161. 2015

[28] K. Dyczkowski, A. Wójtowicz, P. Żywica, A. Stachowiak R. Moszyński, and S. Szubert, "An intelligent system for computer-aided ovarian tumor diagnosis", In Intelligent Systems' pp. 335-343. 2015

[29] Y. Qawqzeh, and K.N.A Sattar, "Online Diagnostic Expert System for Detection of Breast Cancer in Saudi Arabia", International Journal of Computer Applications, vol. 113 issue 6, pp.40-47. 2015

[30] A. Hussain, R. Wenbi, Z. Xiaosong, W. Hongyang, and A L. da Silva, "Personal Home Healthcare System for the Cardiac Patient of Smart City Using Fuzzy Logic", Journal of Advances in Information Technology, vol, 7 issue 1, pp. 58-64. 2016

\section{Authors' Profiles}

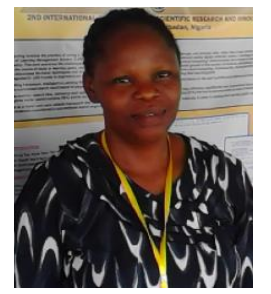

Folasade O. Isinkaye obtained a BSc degree in Computer Science from Ondo State University, Ado Ekiti (now EKSU) and a MSc in Computer Science from University of Ibadan, Nigeria. She is currently a doctoral research student of Computer Science (recommender systems) at the Department of Computer Science, University of Ibadan, Nigeria.

She has lectured at Akanu Ibiam Federal Polytechnic, Unwana, Ebonyi State, National Open University (NOUN), Ado-Ekiti Study Center, The University of Education, IkereEkiti (TUNEDIK) and University of Science and Technology, Ifaki-Ekiti (USTI). She currently lectures at the Department of Computer Science, Ekiti State University, Ado Ekiti, Nigeria. She has published papers in learned journals such as Journal of Global Information Management, Journal of Library Metadata, Egyptian Informatics Journal (Elsevier). Her research interests include Information filtering Systems, Data Mining and computational intelligence

Mrs Isinkaye is a member of professional bodies such as Computer Professional (Registration Council of Nigeria (CPN)) and Association of Computing Machinery (ACM). She is a visiting $\mathrm{PhD}$ scholar at the Laboratory for Knowledge Management, Politecnico di Bari (Technical University), Bari, Italy.

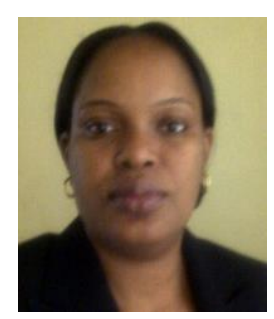

Jumoke Soyemi, had her BSc (Computer Science) at Obafemi Awolowo University, Ile-Ife, MSc (Computer Science) at University of Ibadan and presently running her $\mathrm{PhD}$ (Computer Science) at Covenant University, Ota, Nigeria.

She is an Academic at the Federal Polytechnic, Ilaro, Ogun State Nigeria and currently the head of the department of Computer Science of the same institution. She has served in several capacities and 
worked in different committees of the institution. She has a number of publications in learned journals including "Towards e-health deployment in Nigeria: The open issues", Springer International Publishing Switzerland, ICSIIT 2015, CCIS 516, pp. 588-599, 2015. "Bioinformatics, Healthcare informatics and Analytics: An Imperative for Improved Healthcare", International Journal of Applied Information System, Foundation of Computer Science, 8(5): 1-6, New York, USA and others including conference papers to her credit. She has also won two grants for project implementation from Tertiary and Education Trust Fund (TETFUND) 2015 Intervention, including two travel fellowship awards for training and workshop attendance in South Africa and Tanzania, 2015.

Mrs Soyemi is a member of Computer Professionals of Nigeria (CPN), Nigeria Computer Society (NCS), Fellow in the Institute of Policy Management and Development (FIPMD) as well as student member of International Society for Computational Biology/African Society for Bioinformatics and
Computational Biology (MISCB/ASBCB). She is also an Assessor in the Institute of Chartered Accountant of Nigeria (ICAN).

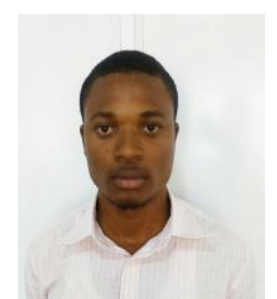

Olayinka P. Oluwafemi holds a BSc degree in Computer Science from the Department of Computer Science, Ekiti State University.

Olayinka P. Oluwafemi is passionate about Software Engineering and his desire is to solve health and other problems with technology, using standard Engineering tools and concepts, thereby, creating productionquality and technologically simplified solutions for current health crisis.

How to cite this paper: Folasade O. Isinkaye, Jumoke Soyemi, Olayinka P. Oluwafemi," A Mobile-based Neuro-fuzzy System for Diagnosing and Treating Cardiovascular Diseases", International Journal of Information Engineering and Electronic Business(IJIEEB), Vol.9, No.6, pp. 19-26, 2017. DOI: 10.5815/ijieeb.2017.06.03 